\title{
ELICITATION OF TRIGONELLINE, A HYPOGLYCEMIC AGENT IN FENUGREEK SPROUTS BY CALCIUM AND NITRIC OXIDE PRIMING
}

\author{
GUPTA SK ${ }^{1}$, NANDA AK ${ }^{2}$, GHOSH $\mathbf{R}^{2}$, MANDAL $\mathbf{P}^{1 *}$ \\ ${ }^{1}$ Department of Botany, Plant Physiology and Pharmacognosy Research Laboratory, University of North Bengal, Siliguri, West Bengal, \\ India. ${ }^{2}$ Department of Chemistry, University of North Bengal, Siliguri, West Bengal, India. Email: nbubotanypm@gmail.com
}

Received: 03 January 2016, Revised and Accepted: 09 February 2017

\section{ABSTRACT}

Objective: This work was performed to evaluate the effect of priming with exogenous sources of calcium ion and nitric oxide on the antidiabetic activity and the alkaloid contents of fenugreek sprouts along with isolation and identification of trigonelline, a bioactive alkaloid responsible for hypoglycemic property of fenugreek.

Methods: The fenugreek seeds were pre-treated with calcium chloride (CC), lanthanum chloride (LC) a calcium channel blocker; ethylene glycol-bis (2-aminoethylether) $-\mathrm{N}, \mathrm{N}, \mathrm{N}^{\prime}, \mathrm{N}$ tetra acetic acid (EG) a calcium chelator; sodium nitroprusside (SNP) and 2-(4-carboxyphenyl) -4,4,5,5-tetramethylimidazoline-1-oxyl-3-oxide (CP) a nitric oxide scavenger and germinated for 72 hrs. The sprout extracts were evaluated for their in vitro antidiabetic potential by $\alpha$-amylase and $\alpha$-glucosidase inhibition along with their trigonelline content. Trigonelline was isolated from fenugreek sprouts and identified by Infrared analysis and nuclear magnetic resonance (NMR) spectroscopy.

Results: The results revealed that sprouts pre-treated with CC and SNP exhibited enhanced antidiabetic potential as well as alkaloid content over control; on the other hand, their action was reversed by their antagonists, EG, LC, and CP. The sprouts pre-treated with $2 \mathrm{mM} \mathrm{CC}$ showed the best elicitation of alkaloid content and antidiabetic activity followed by SNP-20 mM.

Conclusions: The study suggests probable involvement of the signaling molecules, calcium ion, and nitric oxide in pathways associated with biosynthesis of bioactive compounds responsible for hypoglycemic activity of fenugreek sprouts one of which being trigonelline.

Keywords: Antidiabetic, Calcium, Fenugreek sprouts, Nitric oxide, Priming, Trigonelline, Nuclear magnetic resonance.

(c) 2017 The Authors. Published by Innovare Academic Sciences Pvt Ltd. This is an open access article under the CC BY license (http://creativecommons. org/licenses/by/4. 0/) DOI: http://dx.doi.org/10.22159/ajpcr.2017.v10i4.16910

\section{INTRODUCTION}

Plants are the basic source of knowledge of modern medicine. Almost all the parts of a plant, namely leaves, flowers, fruits, bark, roots, stem, and seeds are known to have various medicinal properties [1]. The trend of using natural products has increased, and the active plant extracts are frequently screened for new drug discoveries and for the presence of potential bioactive components $[2,3]$

India with the highest number of people suffering from diabetic disorders has been considered as the diabetic capital of the world by the "International Journal of Diabetes in Developing Countries." There is an alarming rise in diabetes patients in India; approximately 3.4 million deaths occur due to complication related to high blood sugar [4].

Diabetes mellitus is a serious metabolic disorder that leads to hyperglycemic condition due to decreased insulin production or inefficient insulin utilization. It is usually characterized by hyperglycemia, lipoprotein abnormalities, high basal metabolic rate, impairment in the activity of important enzymes, and oxidative stress which damages the pancreatic beta cells. It is the most common endocrine disorder which disrupts glucose homeostasis causing severe diabetic associated complications in major organs such as eye, blood vessels, and brain [5,6]. Multiple risk factors responsible for the disease to occur include persistent stress and depression, obesity, environmental pollutants, and sedentary lifestyle [7].

Some of the synthetic antidiabetic components such as metformin, acarbose, biguanides, and voglibose are found to be used clinically in combination with another diet to control diabetes, but moreover, they exhibit adverse side effects after long term use [8-10]. To prevent or overcome the side effects of these synthetic drugs and also to create other safer alternative drug choices, it has become essential to seek other inhibitors for further drug development. Thus, in recent years, several efforts have been made for increasing the availability of glucosidase inhibitors from natural sources $[11,12]$.

Likewise, fenugreek besides having several pharmacological properties it is also reported to possess potent antidiabetic property both in vitro and in vivo system. Fenugreek is known to be a rich source of various bioactive components having a different therapeutical property such as sapogenins, fenugreekine, nicotinic acid, phytic acid, and trigonelline $[13,14]$. Trigonelline is a pyridine alkaloid known to be mostly found in Fabaceae members and is reported to be metabolically active as a hypocholesterolemic agent along with potential hypoglycemic effect [15-18]. Fenugreek has been successfully implemented as antidiabetic remedy for both types I and II diabetes [19]. Moreover, fenugreek has been reported to be enriched with wide spectrum of pharmacological and folkloric significance [20].

This study deals with the isolation and identification of trigonelline by 1-D and 2-D nuclear magnetic resonance (NMR) from fenugreek sprouts. Further, the elicitors of calcium and nitric oxide were applied for the enhancement in the alkaloid content of fenugreek sprouts along with the in vitro antidiabetic property. This study may provide an insight in the role of these signaling molecules in modulating the biosynthesis of alkaloids, a potential hypoglycemic agent; in addition, the utility of 2-D NMR spectroscopy in identification of bioactive compounds. 


\section{METHODS}

\section{Priming and sprouting}

The fenugreek seeds were surface sterilized with $0.1 \%$ sodium hypochlorite solution. After sterilization, the seeds were washed thrice with distilled water and subjected to priming with the solutions of calcium chloride (CC), an exogenous source of calcium ion; a calcium chelator: Ethylene glycol-bis (2-aminoethylether)- $\mathrm{N}, \mathrm{N}, \mathrm{N}^{\prime}, \mathrm{N}$, tetra acetic acid (EG); a calcium channel blocker: Lanthanum chloride (LC); sodium nitroprusside (SNP) as an exogenous source of nitric oxide and 2-(4-carboxyphenyl)-4,4,5,5-tetramethylimidazoline-1-oxyl-3-oxide (CP), a nitric oxide scavenger. The priming agents applied in various combinations are given in Table 1. For control set, seeds were primed with normal water and kept in a rotary shaker along with the treated seeds. After priming for $24 \mathrm{hrs}$, the seeds were again washed thrice with sterile water and kept in the seed germinator for germination for 72 hrs.

\section{Determination of antidiabetic property by in vitro method \\ Preparation of extract}

The fenugreek sprouts of three different stages: $24 \mathrm{hrs}, 48 \mathrm{hrs}$, and $72 \mathrm{hrs}$ were crushed in mortar-pestle and individually processed through Soxhlet extraction apparatus with methanol for 8 hrs duration. The refluxed samples were separated from the residues by filtering through Whatman No. 1 filter paper, and the extract was concentrated to a uniform concentration of $1 \mathrm{~g} / \mathrm{ml}$ using a vacuum rotary evaporator at $50^{\circ} \mathrm{C}$. The obtained methanolic extracts were further used for experimental analysis for determination of antidiabetic activity and total alkaloid estimation.

\section{Inhibition of $\alpha$-amylase (AA) enzyme activity}

The AA inhibition potential of the extract was estimated by standard spectrophotometric method [21]. $0.5 \mathrm{ml}$ of aqueous extract was reacted with $0.5 \mathrm{ml}$ of AA solution and incubated at $37^{\circ} \mathrm{C}$ for 5 minutes. After incubation, $0.5 \mathrm{ml}$ starch solution $(1 \%)$ was added and was further incubated for 10 minutes. To the above reaction mixture, $1 \mathrm{ml}$ of DNSA reagent was added to terminate the reaction and was heated for 10 minutes in a hot water bath till the color of reaction mixture color changed to orange-red. After change in color, the reaction mixture was cooled and diluted up to $5 \mathrm{ml}$ with distilled water. The OD value was measured at $540 \mathrm{~nm}$. The AA inhibitory activity was estimated by measuring the concentration of inhibitor required to inhibit $50 \%$ of the enzyme activity.

$\%$ inhibition $=\left(\mathrm{A}_{540 \text { control }}-\mathrm{A}_{540 \text { sample }}\right) /\left(\mathrm{A}_{540 \text { control }}\right) \times 100$

Where $A_{540 \text { control }}=$ Absorbance of control at $540 \mathrm{~nm}$ and $\mathrm{A}_{540 \text { sample }}=$ Absorbance of sample at $540 \mathrm{~nm}$.

\section{Inhibition of $\alpha$-glucosidase (AG) enzyme activity}

The AG inhibitory property of the sample extract was assayed according to Dong et al. [22] with slight modifications. The reaction was initiated with $0.05 \mathrm{ml}$ each of the samples at different

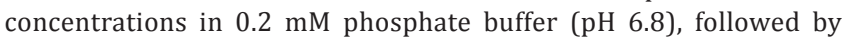
incubation at $37^{\circ} \mathrm{C}$ for 15 minutes, after which $0.1 \mathrm{ml}$ of enzyme solution was immediately added to the mixture before mixing and incubation at $37^{\circ} \mathrm{C}$. Then, $3 \mathrm{mM}$ p-nitrophenyl glucopyranoside (pNPG) $(0.25 \mathrm{ml})$ was added, after which the reaction was terminated by the addition of $4 \mathrm{ml}$ of $0.1 \mathrm{M} \mathrm{Na}_{2} \mathrm{CO}_{3}$. AG inhibitory activity was determined by measuring the release of pNPG at $405 \mathrm{~nm}$. The control contained all reagents without the tested sample. The reactions were conducted in triplicate. The AG inhibitory activity was calculated as follows:

Inhibitory ratio $\%=\left[1-\frac{\left(A_{s}-A_{b}\right)}{A_{c}}\right] \times 100$

Where $A_{c^{\prime}} A_{s^{\prime}}$ and $A_{b}$ represent the absorbance levels of the control, sample, and blank, respectively. The concentration of AG inhibitor required to inhibit $50 \%$ of $A G$ activity under the assay conditions is defined as the concentration inhibition $50 \%\left(\mathrm{IC}_{50}\right)$ value.

\section{Total alkaloid estimation}

The extract was gently heated, and methanol was evaporated on a rotary evaporator under vacuum at a temperature of $45^{\circ} \mathrm{C}$ to dryness. The residue was dissolved in $2 \mathrm{~N} \mathrm{HCl}$ and then filtered. $1 \mathrm{ml}$ of this solution was transferred to a separation funnel and washed with $10 \mathrm{ml}$ chloroform (3 times). The $\mathrm{pH}$ of this solution was adjusted to neutral with $0.1 \mathrm{~N} \mathrm{NaOH}$. Then, $5 \mathrm{ml}$ of Bromocresol Green solution and $5 \mathrm{ml}$ of phosphate buffer were added to this solution. The mixture was shaken and the complex formed was extracted with $5 \mathrm{ml}$ chloroform by vigorous shaking. The extracts were collected in a $10 \mathrm{ml}$ volumetric flask and diluted to the same volume with chloroform. The absorbance of the complex in chloroform was measured at $470 \mathrm{~nm}$ against blank [23]. Similarly, trigonelline content was also estimated from the purified extract.

\section{Isolation of trigonelline}

The extraction procedure was followed as suggested by Ahmed et al. [24] with some modifications. The fenugreek sprouts of about $100 \mathrm{~g}$ were homogenized in $10 \mathrm{M} \mathrm{HCl}$ solution and gently boiled for $2 \mathrm{hrs}$ in an Erlenmeyer flask. Next, the mixture was filtered, and zinc dust was added to the mixture and kept on a magnetic stirrer for overnight. In next morning, the mixture was filtered again and extracted with equal volume of dichloromethane $\left(\mathrm{CH}_{2} \mathrm{Cl}_{2}\right)$. The $\mathrm{CH}_{2} \mathrm{Cl}_{2}$ layer containing the alkaloid was separated and later evaporated. The obtained extract after $\mathrm{CH}_{2} \mathrm{Cl}_{2}$ evaporation was reconstituted in methanol for further analysis.

\section{Thin layer chromatography (TLC)}

The extract dissolved in methanol was applied manually on activated TLC plates, along with standard trigonelline. After loading the samples, the TLC plates were developed in presaturated chromatography solvent chamber containing solvent system composed of ethylacetate:methanol: $\mathrm{H}_{2} \mathrm{O}$ (100:13.5:10). After running the solvent through the TLC plates, the plates were sprayed with Dragendorff's reagent to develop spot corresponding to standard trigonelline simultaneously.

After confirming the presence of trigonelline, in next TLC experiment after running the solvent through the TLC plate, the portion of plate containing pure trigonelline was cut and sprayed with Dragendorff's reagent and then the area of TLC plate containing unknown extract corresponding to band developed on the plate with standard trigonelline was scrapped and collected, dried and later dissolved in methanol for further quantitative, and spectral analysis.

\section{Infrared (IR) spectral analysis}

IR spectra of the crude, purified sample and standard trigonelline were recorded on FTIR spectrophotometer (model: 8300 Shimadzu) by Nujol mulling for liquid sample and $\mathrm{KBr}$ pellets for solid sample.

Table 1: Different priming agents applied

\begin{tabular}{|c|c|c|c|}
\hline \multicolumn{2}{|c|}{ Calcium elicitors } & \multicolumn{2}{|c|}{ Nitric oxide elicitors } \\
\hline T0 & $\mathrm{H}_{2} \mathrm{O}$ & T0 & $\mathrm{H}_{2} \mathrm{O}$ \\
\hline Tc1 & $\mathrm{CC}^{2}-1 \mathrm{mM}$ & $\operatorname{Tn} 1$ & $\mathrm{SNP}^{2}-10 \mathrm{mM}$ \\
\hline Tc2 & CC- $2 \mathrm{mM}$ & $\operatorname{Tn} 2$ & SNP-20 mM \\
\hline Tc3 & CC-5 mM & Tn3 & SNP-40 mM \\
\hline Tc4 & $\mathrm{CC}-1 \mathrm{mM}+\mathrm{EG} 500 \mu \mathrm{M}$ & Tn4 & SNP-80 mM \\
\hline Tc5 & $\mathrm{CC}-2 \mathrm{mM}+\mathrm{EG} 500 \mu \mathrm{M}$ & Tn5 & SNP-120 mM \\
\hline Тc6 & CC-5 mM+EG500 $\mu \mathrm{M}$ & Tn6 & SNP10 mM+CP125 $\mu \mathrm{M}$ \\
\hline Tc7 & $\mathrm{EG}-2 \mathrm{mM}$ & Tn7 & SNP20 mM+CP125 $\mu \mathrm{M}$ \\
\hline Тс8 & CC-1 mM+LC500 $\mu \mathrm{M}$ & Tn8 & SNP40 mM+CP125 $\mu \mathrm{M}$ \\
\hline Тс9 & CC-2 mM+LC500 $\mu \mathrm{M}$ & $\operatorname{Tn} 9$ & SNP80 mM+CP125 $\mu \mathrm{M}$ \\
\hline Tc10 & CC-5 mM+LC500 $\mu \mathrm{M}$ & Tn10 & SNP120 mM+CP125 $\mu \mathrm{M}$ \\
\hline Tc11 & LC-2 mM & Tn11 & $\mathrm{CP} 125 \mu \mathrm{M}$ \\
\hline
\end{tabular}




\section{NMR analysis}

The confirmation of the structure of the extracted compound was done by NMR-spectra in 300 MHZ Bruker-Avance spectrometer using $5 \mathrm{~mm}$ BBO probe and Methanol-d4 was used as a solvent.

\section{Statistical analysis}

Each experiment was performed in triplicate. The software package, MS Excel 2007 (Microsoft, Redmond, WA, USA) was used for comparing the antidiabetic activity and alkaloid content of the fenugreek sprouts. The different group means were compared by Tukey's multiple range test through DSAASTAT software (version 1.002; DSAASTAT, Perugia, Italy); $<<0.05$ was considered significant in all cases. Smith's Statistical Package version 2.5 (prepared by Gary Smith, CA, USA) was used for determining the $\mathrm{IC}_{50}$ values of antidiabetic activity and their standard error of estimates.

\section{RESULTS AND DISCUSSION}

The key enzymes in the digestive system, AA and AG are actively involved in the release of glucose in the blood via breakdown of starch. Hence, the inhibition of these enzymes would minimize the breakdown of starch, which may lead to a reduction in the post-prandial hyperglycemic level [25]. Therefore, determination of the capability of an extract to inhibit the activity of these enzymes AA and AG is essential for investigating the antidiabetic potentiality of the extract. Since fenugreek has been well known for its antidiabetic activity, this study aimed at enhancing the antidiabetic activity of fenugreek sprouts through elicited sprouting. The inhibition capacity of the sprouts was expressed in terms of $\mathrm{IC}_{50}$ values. The results revealed that the fenugreek sprouts exhibited potential antidiabetic property, and interestingly, it was also observed that the exogenous supply of $\mathrm{Ca}^{2+}$ and nitric oxide resulted in the enhancement of this activity in fenugreek sprouts. Both
AA and AG inhibition capacity of fenugreek sprouts was enhanced by CC (Table 2) and SNP (Table 3).

In many plant species alkaloids getaccumulated in seeds in relatively high concentration as a chemical defense. During germination, alkaloids get metabolized, and their nitrogen is reused for seedling's metabolism [26]. The antidiabetic property of most legumes including fenugreek is usually attributed to their trigonelline content, an alkaloid with scientifically well characterized hypoglycemic effect [14,27]. Trigonelline is reported to act by regulating cell regeneration, insulin secretion, enzymes associated with glucose metabolism. It is further known to mitigate oxidative stress during the diabetic complications $[28,29]$. Considering such potential role of alkaloids in controlling the diabetic disorders, the alkaloid content of the fenugreek seedlings subjected to various priming agents was determined. Interestingly, it was found that the sprouts pre-treated with CC and SNP exhibited significantly higher alkaloid content with respect to control sprouts. Similar trend in the effect of different priming agent was observed in the trigonelline content of the fenugreek sprouts (Fig. 1). The potential hypoglycemic property of trigonelline was further supported by our results which clearly depicted the significant influence of trigonelline content on the AG (Fig. 2) and AA (Fig. 3) inhibitory capacity of fenugreek sprouts pre-treated with different priming agents. On the other hand, the antagonists, EG, LC, and CP showed inhibitory effect on the alkaloid accumulation in the sprouts. In agreement to the earlier cited statement, it was noted that the sprouts with the higher trigonelline content exhibited stronger AG and AA inhibition activity thus suggesting the probable role of alkaloids especially trigonelline as hypoglycemic compounds in the management of diabetic disorders. Furthermore, various authors have proved that the enhancement in the hypoglycemic activity of fenugreek is considerably associated with an increase in the level of bioactive components such as trigonelline and 4-hyroxy leucine $[24,30,31]$.

Table 2: In vitro AA and $\alpha$-glucosidase inhibition activity of fenugreek sprouts under the influence of different calcium elicitors

\begin{tabular}{|c|c|c|c|c|c|c|}
\hline \multirow[t]{2}{*}{ Treatment } & \multicolumn{2}{|l|}{$24 \mathrm{hrs}$} & \multicolumn{2}{|l|}{$48 \mathrm{hrs}$} & \multicolumn{2}{|l|}{$72 \mathrm{hrs}$} \\
\hline & $\mathrm{AG}(\mathrm{mg} / \mathrm{ml})$ & $\mathrm{AA}(\mathrm{mg} / \mathrm{ml})$ & $\mathrm{AG}(\mathrm{mg} / \mathrm{ml})$ & $\mathrm{AA}(\mathrm{mg} / \mathrm{ml})$ & $\mathrm{AG}(\mathrm{mg} / \mathrm{ml})$ & $\mathrm{AA}(\mathrm{mg} / \mathrm{ml})$ \\
\hline T0 & $1010 \pm 47.76^{\mathrm{b}}$ & $1186.75 \pm 38.72^{c}$ & $715.20 \pm 31.24^{c}$ & $840.36 \pm 42.36^{d}$ & $1122.81 \pm 29.98^{\mathrm{d}}$ & $1319.30 \pm 24.21^{c}$ \\
\hline Tc1 & $336.52 \pm 28.05^{a}$ & $619.20 \pm 15.02^{\mathrm{b}}$ & $330.0 \pm 22.37^{a}$ & $607.20 \pm 12.08^{\mathrm{b}}$ & $717.50 \pm 21.94^{\mathrm{b}}$ & $1320.20 \pm 19.12^{c}$ \\
\hline Tc2 & $339.42 \pm 22.32^{\mathrm{a}}$ & $522.71 \pm 10.33^{a}$ & $301.12 \pm 13.77^{a}$ & $463.71 \pm 20.48^{\mathrm{a}}$ & $599.80 \pm 17.04^{\mathrm{a}}$ & $923.69 \pm 14.34^{\mathrm{a}}$ \\
\hline Tc3 & $348.94 \pm 16.69^{a}$ & $502.48 \pm 12.05^{\mathrm{a}}$ & $464.68 \pm 23.13^{b}$ & $669.15 \pm 23.95^{c}$ & $795.38 \pm 18.69^{c}$ & $1145.35 \pm 12.72^{b}$ \\
\hline Tc4 & $1055.23 \pm 22.42^{\mathrm{b}}$ & $1202.97 \pm 32.15^{c}$ & $773.20 \pm 16.08^{\mathrm{d}}$ & $1345.36 \pm 27.99^{i}$ & $1176.25 \pm 27.24^{\mathrm{d}}$ & $1576.17 \pm 18.79^{\mathrm{e}}$ \\
\hline Tc5 & $1593.33 \pm 12.54^{\mathrm{d}}$ & $1386.20 \pm 36.44^{\mathrm{e}}$ & $1289.22 \pm 18.33^{g}$ & $1121.43 \pm 11.86^{\mathrm{f}}$ & $1869.88 \pm 39.97^{\mathrm{h}}$ & $1626.79 \pm 16.76^{\mathrm{ef}}$ \\
\hline Tc6 & $1634.5 \pm 15.69^{\mathrm{d}}$ & $1291.97 \pm 9.56^{\mathrm{d}}$ & $1610.71 \pm 25.36^{\mathrm{h}}$ & $1272.46 \pm 13.40^{\mathrm{h}}$ & $1906.36 \pm 23.15^{\mathrm{h}}$ & $1506.02 \pm 23.17^{\mathrm{d}}$ \\
\hline Tc7 & $2276.66 \pm 29.58^{\mathrm{e}}$ & $1707.50 \pm 24.45^{\mathrm{f}}$ & $1732.11 \pm 17.87^{\mathrm{i}}$ & $1299.08 \pm 13.25^{\mathrm{hi}}$ & $2284.50 \pm 13.73^{\mathrm{i}}$ & $1713.37 \pm 13.90^{\mathrm{g}}$ \\
\hline Tc8 & $1047.41 \pm 10.56^{\mathrm{b}}$ & $1199.29 \pm 13.22^{c}$ & $832.85 \pm 12.42^{\mathrm{e}}$ & $953.63 \pm 10.55^{\mathrm{e}}$ & $1326.92 \pm 15.67^{\mathrm{e}}$ & $1519.32 \pm 17.09^{\mathrm{d}}$ \\
\hline Tc9 & $1141.54 \pm 12.36^{c}$ & $1284.23 \pm 12.42^{\mathrm{d}}$ & $1075.21 \pm 19.11^{\mathrm{f}}$ & $1209.62 \pm 19.23^{g}$ & $1598.89 \pm 17.14^{\mathrm{f}}$ & $1798.75 \pm 20.33^{\mathrm{h}}$ \\
\hline Tc10 & $1148.09 \pm 9.44^{c}$ & $1287.02 \pm 8.56^{\mathrm{d}}$ & $1258.18 \pm 12.45^{g}$ & $1410.42 \pm 17.19^{j}$ & $1738.04 \pm 12.05^{\mathrm{g}}$ & $1885.77 \pm 18.90^{\mathrm{i}}$ \\
\hline Tc11 & $2545 \pm 34.22^{\mathrm{f}}$ & $1679.70 \pm 22.72^{\mathrm{f}}$ & $1294.58 \pm 14.62^{\mathrm{g}}$ & $1513.34 \pm 12.14^{\mathrm{k}}$ & $1700.80 \pm 11.36^{\mathrm{g}}$ & $1632.76 \pm 18.24^{\text {df }}$ \\
\hline
\end{tabular}

Results are represented as mean \pm standard error of mean, $n=3$. Values with different letters ( $a-k)$ are significantly $(p<0.05)$ different from each other by Tukey's multiple range test, AA: $\alpha$-amylase

Table 3: In vitro AA and $\alpha$-glucosidase inhibition activity of fenugreek sprouts under the influence of different nitric oxide elicitors

\begin{tabular}{|c|c|c|c|c|c|c|}
\hline \multirow[t]{2}{*}{ Treatment } & \multicolumn{2}{|l|}{$24 \mathrm{hrs}$} & \multicolumn{2}{|l|}{$48 \mathrm{hrs}$} & \multicolumn{2}{|l|}{$72 \mathrm{hrs}$} \\
\hline & $\mathrm{AG}(\mathrm{mg} / \mathrm{ml})$ & $\mathrm{AA}(\mathrm{mg} / \mathrm{ml})$ & $\mathrm{AG}(\mathrm{mg} / \mathrm{ml})$ & $\mathrm{AA}(\mathrm{mg} / \mathrm{ml})$ & AG (mg/ml) & $\mathrm{AA}(\mathrm{mg} / \mathrm{ml})$ \\
\hline T0 & $1010 \pm 47.76^{\mathrm{e}}$ & $1186.75 \pm 38.72^{\mathrm{de}}$ & $715.20 \pm 31.24^{c}$ & $840.36 \pm 42.36^{\mathrm{d}}$ & $1122.81 \pm 29.98^{\mathrm{d}}$ & $1319.30 \pm 24.21^{c}$ \\
\hline Tn1 & $533.33 \pm 22.16^{\mathrm{b}}$ & $981.33 \pm 11.05^{c}$ & $420.01 \pm 9.22^{\mathrm{ba}}$ & $772.8 \pm 8.72^{\mathrm{c}}$ & $765.14 \pm 21.94^{\mathrm{b}}$ & $1407.86 \pm 18.44^{\mathrm{d}}$ \\
\hline Tn2 & $377.86 \pm 12.78^{a}$ & $581.90 \pm 12.62^{\mathrm{a}}$ & $350.91 \pm 8.56^{a}$ & $540.41 \pm 7.16^{\mathrm{a}}$ & $630.38 \pm 17.04^{\mathrm{a}}$ & $970.78 \pm 8.54^{a}$ \\
\hline Tn3 & $635.81 \pm 8.15^{c}$ & $915.57 \pm 9.29^{b}$ & $451 \pm 11.05^{\mathrm{b}}$ & $649.44 \pm 7.95^{\mathrm{b}}$ & $839.75 \pm 18.69^{c}$ & $1209.25 \pm 12.05^{b}$ \\
\hline Tn4 & $822.96 \pm 12.33^{\mathrm{d}}$ & $1431.95 \pm 12.67^{\mathrm{f}}$ & $836.32 \pm 12.06^{\mathrm{d}}$ & $1455.21 \pm 18.52^{\mathrm{g}}$ & $1215.47 \pm 27.24^{\mathrm{e}}$ & $2114.92 \pm 22.48^{\mathrm{i}}$ \\
\hline Tn5 & $1313.16 \pm 11.22^{\mathrm{g}}$ & $1497.0 \pm 26.38^{\mathrm{g}}$ & $1464.12 \pm 19.14^{\mathrm{i}}$ & $1669.09 \pm 18.32^{\mathrm{h}}$ & $1962.27 \pm 39.97^{\mathrm{i}}$ & $2236.99 \pm 19.86^{j}$ \\
\hline Tn6 & $1341.30 \pm 12.56^{\mathrm{gh}}$ & $1166.93 \pm 9.08^{\mathrm{d}}$ & $1354.88 \pm 14.17^{\mathrm{h}}$ & $1178.75 \pm 10.22^{\mathrm{f}}$ & $2375.56 \pm 23.15^{j}$ & $2066.73 \pm 21.62^{\mathrm{hi}}$ \\
\hline Tn7 & $1160.0 \pm 9.42^{\mathrm{df}}$ & $1032.40 \pm 14.12^{\mathrm{bc}}$ & $1197.09 \pm 12.32^{\mathrm{f}}$ & $945.71 \pm 8.25^{\mathrm{e}}$ & $1992.78 \pm 13.73^{\mathrm{i}}$ & $1574.29 \pm 18.24^{\mathrm{e}}$ \\
\hline Tn8 & $1071.33 \pm 11.24^{\mathrm{f}}$ & $1229.90 \pm 8.54^{\mathrm{e}}$ & $1146.82 \pm 13.16^{\mathrm{e}}$ & $860.11 \pm 8.66^{\mathrm{d}}$ & $1406.67 \pm 15.67^{f}$ & $1448.86 \pm 16.92^{\mathrm{d}}$ \\
\hline $\operatorname{Tn} 9$ & $1376.40 \pm 13.05^{\mathrm{h}}$ & $1575.97 \pm 14.16^{\mathrm{h}}$ & $1294.28 \pm 12.11^{\mathrm{g}}$ & $1481.95 \pm 18.45^{\mathrm{g}}$ & $1625.24 \pm 17.14^{g}$ & $1860.90 \pm 24.68^{\mathrm{f}}$ \\
\hline Tn10 & $1704.09 \pm 19.19^{j}$ & $1917.0 \pm 17.32^{\mathrm{j}}$ & $1820.76 \pm 22.04^{\mathrm{k}}$ & $2048.36 \pm 24.35^{j}$ & $1819.86 \pm 12.05^{\mathrm{h}}$ & $2047.33 \pm 18.78^{\mathrm{h}}$ \\
\hline Tn11 & $1559.38 \pm 14.22^{\mathrm{i}}$ & $1748.06 \pm 21.41^{\mathrm{i}}$ & $1608.13 \pm 14.28^{j}$ & $1802.71 \pm 22.08^{\mathrm{i}}$ & $1768.12 \pm 11.36^{\mathrm{h}}$ & $1982.06 \pm 21.86^{\mathrm{g}}$ \\
\hline
\end{tabular}

Results are represented as mean \pm standard error of mean, $n=3$. Values with different letters (a-k) are significantly $(p<0.05)$ different from each other by Tukey's multiple range test, AA: $\alpha$-amylase 
Further, two-way ANOVA analysis with replication was performed to determine the impact of different priming agents and various germination stages on antidiabetic and trigonelline content of fenugreek sprouts. As a result, a significant impact of both variance, i.e., priming agents and germination stages was found on the AA and AG inhibitory activity along with the trigonelline content (Table 4). Interactions between both were also significant at $\mathrm{p}<0.05$ level.

The crude and purified extracts of fenugreek sprout were subjected to IR spectral analysis. The finger print region of both crude and purified extracts matched exactly with the that of standard trigonelline (Fig. 5), this indicates all the samples are of same nature, and further confirms the predominance of trigonelline in both extracts (crude and purified). In the frequency range 3000 to $3500 \mathrm{~cm}^{-1}$ broad strong absorption indicates the presence of $-\mathrm{OH}$ groups, both intra and intermolecular $\mathrm{H}$-bonded. At $1715 \mathrm{~cm}^{-1}$ the absorption corresponds the presence of carboxylic acid group. The presence of some sharp medium absorption peaks at around $2725 \mathrm{~cm}^{-1}$ indicates the presence of $\mathrm{C}=\mathrm{C}-\mathrm{H}$ aromatic bonds supported by the presence of aromatic ring unsaturation vibrational bands around $1600 \mathrm{~cm}^{-1}$, the weak absorption for the ring bending of benzene derivatives in the range of $900 \mathrm{~cm}^{-1}$ was also observed. The aliphatic C-H stretching modes at around $2900 \mathrm{~cm}^{-1}$ are masked with that of the Nujol. After confirming, the presence of trigonelline in purified extract by IR analysis the extract was further analyzed by NMR spectroscopy.

The implementation of NMR spectroscopy for metabolite fingerprinting has been considered highly reliable by the researchers. One-dimensional NMR (1D-NMR) spectra have been used successfully for analyzing compounds in a crude extract, further two-dimensional NMR (2D-NMR) spectra have been reported to be more efficient in the identification of bioactive compounds in plant extracts [32,33]. Likewise, the purified extract was subjected to 2D-NMR for the identification of compound. The proton $\left({ }^{1} \mathrm{H}\right)$ NMR spectra derived from the purified extract of fenugreek were characterized by $\mathrm{N}^{+}-\mathrm{CH} 3(3 \mathrm{H})$ peak at $4.5 \mathrm{ppm}(\delta)$;

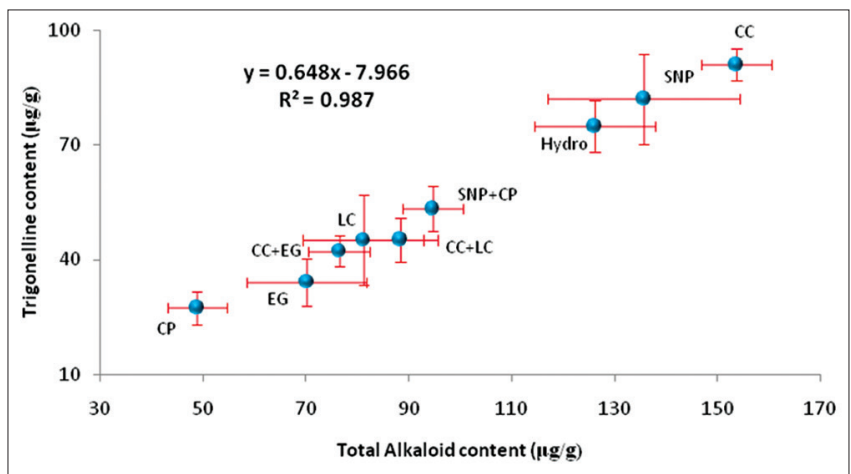

Fig. 1: Effect of different priming agents on the total alkaloid and trigonelline contents of fenugreek sprouts

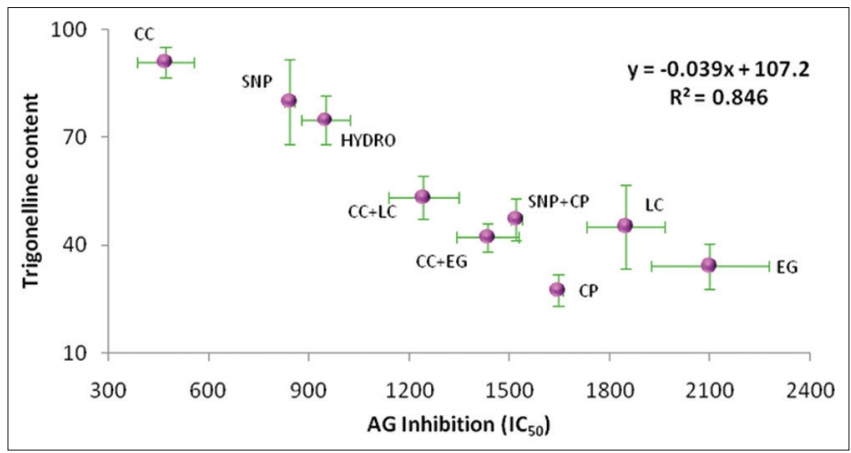

Fig. 2: Effect of different priming agents on the trigonelline contents and $\alpha$-glucosidase inhibition activity of fenugreek sprouts aromatic protons are observed at $8.1 \mathrm{ppm}(\delta)(1 \mathrm{H})$, at $9 \mathrm{ppm}(\delta)$ $(2 \mathrm{H})$ and at $9.3 \mathrm{ppm}(\delta)(1 \mathrm{H})$. In proton correlated spectroscopy and total correlation spectroscopy spectra, the correlation of the protons is confirmed and in the heteronuclear correlation spectra correlation of the spectra with that of carbon shifts are ascertained. This spectral analysis unequivocally suggests that the purified extract contains 1-methylpyridinium-3-carboxylate (trigonelline). The ${ }^{1} \mathrm{H}$ NMR spectra of purified fenugreek extract are depicted in (Figs. 5 and 6). The other spectra are annexed in the supplementary files.

Overall, it was observed that among all treatments, CC and SNP priming exhibited enhancement in the alkaloid and antidiabetic potential of fenugreek, among which CC was found to exhibit the best result. Such enhancement in the antidiabetic activity and the level of trigonelline in fenugreek has reported by various authors through biotic and abiotic elicitors [24,34]. The therapeutic property of trigonelline is highly attributed to its hypoglycemic effect, thus the enhancement in the biosynthesis of alkaloids further boosts the antidiabetic potential of the plant. The observation of best antidiabetic activity of sprouts during $48 \mathrm{hrs}$ stage indicates that the components including trigonelline responsible for the therapeutic potential were elicited appropriately at this stage. The impact of nitric oxide scavenger (CP), calcium chelator (EG) and calcium channel blocker was also assessed on the antidiabetic as well as alkaloid content of the fenugreek sprouts. The effect of these elicitors was found to be deteriorative on both aspects of the sprouts, i.e., therapeutic (antidiabetic) as well phytochemical (alkaloid) content.

\section{CONCLUSION}

It can be suggested that the increase in the alkaloid content was found to be responsible for the enhancement in antidiabetic property of fenugreek sprouts. The negative effects of the antagonists of calcium and nitric oxide indicate that the flux of these signaling molecules within the cellular system is essential during germination phases to regulate

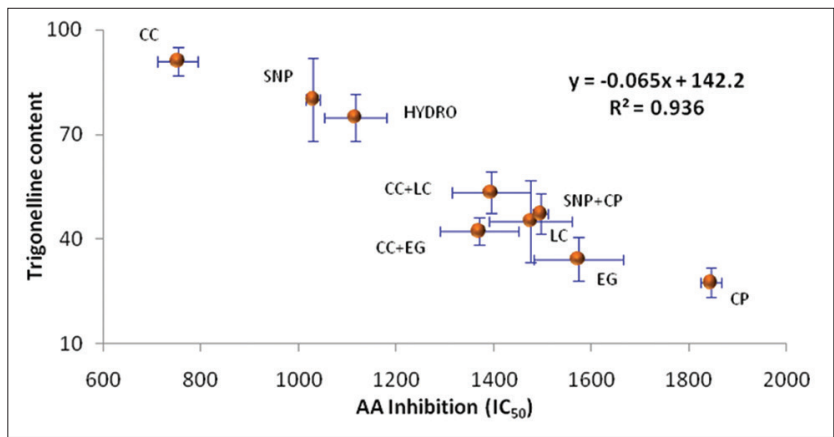

Fig. 3: Effect of different priming agents on the trigonelline contents and $\alpha$-amylase inhibition activity of fenugreek sprouts

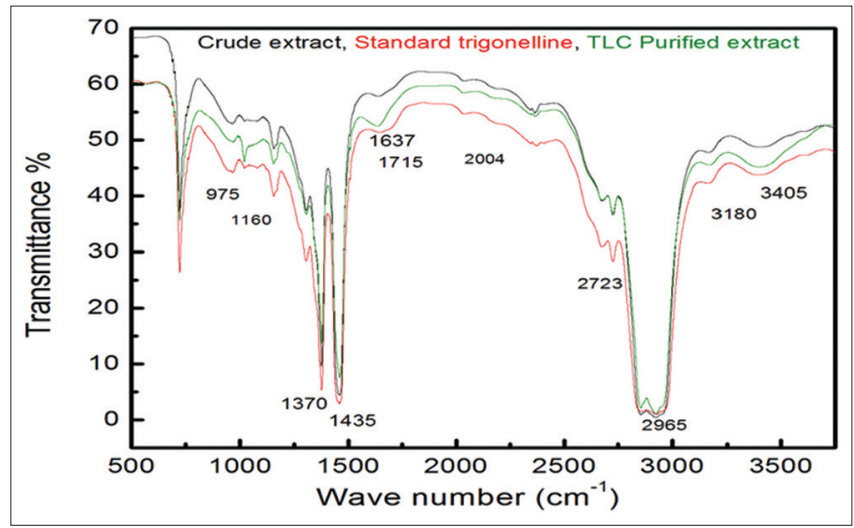

Fig. 4: Infrared spectra of crude extract and thin layer chromatography purified extract compared with standard trigonelline 
Table 4: Two-way ANOVA analysis of antidiabetic and trigonelline content of differently primed fenugreek sprouts at various days of germination stage

\begin{tabular}{|c|c|c|c|c|c|c|c|c|}
\hline \multirow[t]{2}{*}{ Source of variation } & \multirow[t]{2}{*}{ df } & \multirow[t]{2}{*}{ Free critical } & \multicolumn{2}{|l|}{ AG } & \multicolumn{2}{|l|}{ AA } & \multicolumn{2}{|l|}{ TC } \\
\hline & & & $\mathbf{F}$ & $\mathbf{p}^{*}$ & $\mathbf{F}$ & $\mathbf{p}^{*}$ & $\mathbf{F}$ & $\mathbf{p}^{*}$ \\
\hline Treatment & 23 & 1.604555 & 91163.68 & $1.1 \mathrm{E}-287$ & 70049.33 & $1.8 \mathrm{E}-279$ & 1314.238 & $2.6 \mathrm{E}-155$ \\
\hline Days of germination & 2 & 3.058928 & 131427.4 & $1.5 \mathrm{E}-235$ & 178824.7 & $3.5 \mathrm{E}-245$ & 1838.919 & $3 E-103$ \\
\hline Interaction & 46 & 1.453191 & 4813.891 & $5.2 E-209$ & 7558.876 & $4.1 \mathrm{E}-223$ & 69.94316 & $1.9 \mathrm{E}-78$ \\
\hline Within & 144 & & & & & & & \\
\hline Total & 215 & & & & & & & \\
\hline
\end{tabular}

*Significant at $\mathrm{p}<0.01, \mathrm{AG}$ : $\alpha$-glucosidase, AA: $\alpha$-amylase

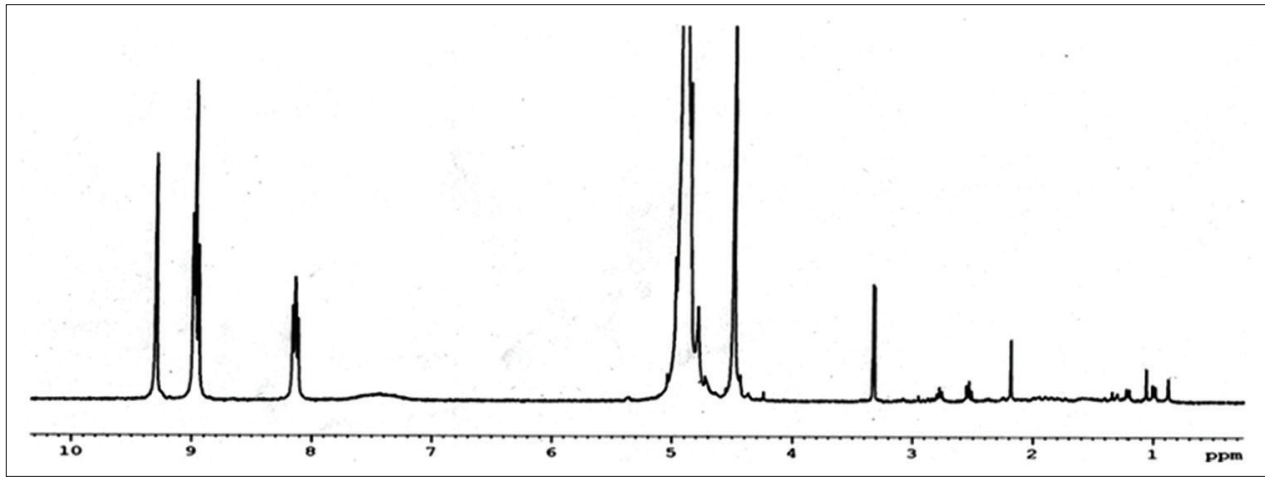

Fig. 5: ${ }^{1} \mathrm{H}$ NMR spectra of thin layer chromatography purified extract of fenugreek sprout

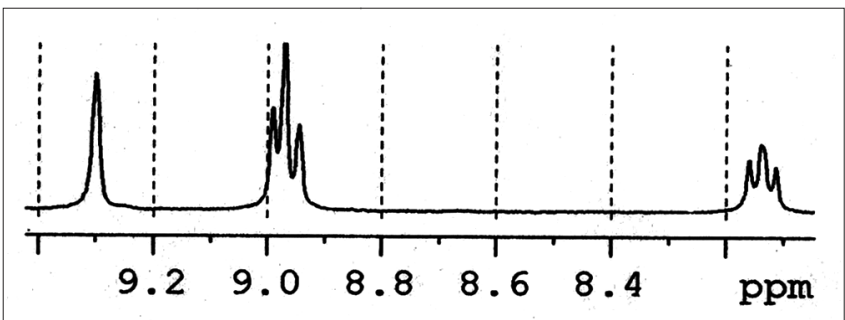

Fig. 6: Expanded regions of ${ }^{1} \mathrm{H}$ NMR spectra of thin layer chromatography purified extract of fenugreek sprout

the mechanisms responsible for the biosynthesis of antidiabetic compounds. The presence of trigonelline as a major alkaloid component was further confirmed by IR and NMR analysis. Thus, this knowledge can be used to design the priming based sprouting techniques which might have potential application in improving the nutraceutical quality of legume sprouts.

\section{ACKNOWLEDGMENT}

The authors gratefully acknowledge the Department of Science and Technology for providing financial aid for this research work under INSPIRE scheme.

\section{REFERENCES}

1. Mori SA, Prance GT. Additional notes on the floral biology of neotropical Lecythidaceae. Brittonia 1978;30:113-30.

2. Luximon-Ramma A, Bahorun T, Soobrattee MA, Aruoma OI. Antioxidant activities of phenolic, proanthocyanidin, and flavonoid components in extracts of Cassia fistula. J Agric Food Chem 2002;50(18):5042-7.

3. Senthilkumar P, Sudha S, Prakash S. Antidiabetic activity of aqueous extract of Padina boergesenii in streptozotocin-induced diabetic rats. Int J Pharm Pharm Sci 2014;6:418-22.

4. Kumar KP, Bhowmik D, Srivastava S, Paswan S, Dutta A. Diabetes epidemic in India-A comprehensive review of clinical features, management and remedies. Pharm Innov 2012;1(2):17-33.

5. Sharma VK, Kumar S, Patel HJ, Hugar S. Hypoglycemic activity of Ficus glomerata in alloxan induced diabetic rats. Int J Pharm Sci Rev
Res 2010;1(2):18-22

6. Jaiswal J, Bhardwaj H, Srivastava S, Gautam H, Sharma S. Antidiabetic activity of methanolic extract of Calotropis gigantea seeds on stz induced diabetic rats. Int J Pharm Pharm Sci 2014;6:254-7.

7. Ghamarian A, Abdollahi M, Su X, Amiri A, Ahadi A, Nowrouzi A. Effect of chicory seed extract on glucose tolerance test (GTT) and metabolic profile in early and late stage diabetic rats. Daru 2012;20(9):56.

8. Asano N. Sugar-mimicking glycosidase inhibitors: Bioactivity and application. Cell Mol Life Sci 2009;66(9):1479-92.

9. Standl E, Schnell O. Alpha-glucosidase inhibitors 2012-cardiovascular considerations and trial evaluation. Diab Vasc Dis Res 2012;9:163-9.

10. Patel DK, Prasad SK, Kumar R, Hemalatha S. An overview on antidiabetic medicinal plants having insulin mimetic property. Asian Pac J Trop Biomed 2012;2(4):320-30.

11. Jung M, Park M, Lee HC, Kang YH, Kang ES, Kim SK. Antidiabetic agents from medicinal plants. Curr Med Chem 2006;13(10):1203-18.

12. Jin H, Zhang YJ, Jiang JX, Zhu LY, Chen P, Li J, et al. Studies on the extraction of pumpkin components and their biological effects on blood glucose of diabetic mice. J Food Drug Anal 2013;21:184-9.

13. Puri D. Therapeutic potentials of fenugreek. Indian J Physiol Pharmacol 1998;42(3):423-4

14. Randhir R, Lin YT, Shetty K. Phenolics, their antioxidant and antimicrobial activity in dark germinated fenugreek sprouts in response to peptide and phytochemical elicitors. Asia Pac J Clin Nutr 2004;13(3):295-307.

15. Evans LS, Almeida MS, Lynn DG, Nakanishi K. Chemical characterization of a hormone that promotes cell arrest in $\mathrm{g} 2$ in complex tissues. Science 1979;203(4385):1122-3.

16. Taguchi H, Muneto S, Shimabayashi Y. Content of quinolic acid trigonelline and $\mathrm{M}$-methyl nicotinamide in various food and thermal conversion of acid and nicotinamide. Betamin 1986;60:537-46.

17. Olthof MR, van Dijk AE, Deacon CF, Heine RJ, van Dam RM. Acute effects of decaffeinated coffee and the major coffee components chlorogenic acid and trigonelline on incretin hormones. Nutr Metab (Lond) 2011;8:10

18. Mathur M, Kamal R. Studies on trigonelline from Moringa oleifera and its in vitro regulation by feeding precursor in cell cultures. Braz J Pharmacogn 2012;22(5):994-1001.

19. Zia T, Hasnain SN, Hasan SK. Evaluation of the oral hypoglycemic effect of Trigonella foenum-graecum L. (Methi) in normal mice. J Ethnopharmacol 2001;75(2-3):191-5.

20. Meghwal M, Goswami TK. A review on the functional properties, nutritional content, medicinal utilization and potential application of fenugreek. J Food Process Technol 2012;3(1):181. 
21. Paul T, Banerjee S. In vitro evaluation of $\alpha$-amylase inhibitory activity and antioxidant potential of Pteris vittata $\mathrm{L}$. with special reference to its HPTLC profile. Int J Pharm Bio Sci 2013;4(2):494-503.

22. Dong HQ, Li M, Zhu F, Liu FL, Huang JB. Inhibitory potential of trilobatin from Lithocarpus polystachyus Rehd against $\alpha$-glucosidase and $\alpha$-amylase linked to Type 2 diabetes. Food Chem 2012;130:261-6.

23. Shamsa F, Monsef H, Ghamooshi R, Verdianrizi M. Spectrophotometric determination of total alkaloids in some Iranian medicinal plants. Thai $\mathrm{J}$ Pharm Sci 2008;32:17-20.

24. Ahmed MA, Abd-El M, Osman HE. Elicitation of trigonelline and 4-hydroxyisoleucine with hypoglycemic activity in cell suspension cultures of Trigonella foenum graecum L. Open Conf Proc J 2011;2:80-7.

25. Wink M, Witte L. Quizalizidine alkaloids as nitrogen source for lupine seedlings and cell suspension cultures. Z Naturforsch C 1985;40:767-75.

26. Tarling CA, Woods $\mathrm{K}$, Zhang $\mathrm{R}$, Brastianos HC, Brayer GD, Andersen RJ, et al. The search for novel human pancreatic alphaamylase inhibitors: High-throughput screening of terrestrial and marine natural product extracts. Chembiochem 2008;9(3):433-8.

27. Yoshinari O, Takenake A, Igarashi K. Trigonelline ameliorates oxidative stress in type 2 diabetic Goto-Kakizaki rats. J Med Food 2013;16(11):34-41.
28. Yoshinari O, Sato H, Igarashi K. Anti-diabetic effects of pumpkin and its components, trigonelline and nicotinic acid, on Goto-Kakizaki rats. Biosci Biotechnol Biochem 2009;73(5):1033-41.

29. Amaro CA, González-Cortazar M, Herrera-Ruiz M, Román-Ramos R, Aguilar-Santamaría L, Tortoriello J, et al. Hypoglycemic and hypotensive activity of a root extract of Smilax aristolochiifolia, standardized on N-trans-feruloyl-tyramine. Molecules 2014;19(8):11366-84.

30. El-Soud NH, Khalil MY, Hussein JS, Oraby FS, Farrag AR. Antidiabetic effects of fenugreek alkaloid extract in streptozotocin induced hyperglycemic rats. J Appl Sci Res 2007;3(10):1073-83.

31. Narender T, Puri A, Shweta, Khaliq T, Saxena R, Bhatia G, et al 4-hydroxyisoleucine an unusual amino acid as antidyslipidemic and antihyperglycemic agent. Bioorg Med Chem Lett 2006;16(2):293-6

32. Kim HK, Choi YH, Verpoorte R. NMR-based metabolomic analysis of plants. Nat Protoc 2010;5(3):536-49.

33. Farag MA, Porzel A, Wessjohann LA. Unravelling the active hypoglycemic agent trigonelline in Balanites aegyptiaca date fruit using metabolite fingerprinting by NMR. J Pharm Biomed Anal 2015;115:383-7.

34. Qaderi A, Akbari Z, Kalateh-Jari S, Fatehi F, Tolyat M, Moghadam MJ, et al. Improving trigonelline production in hairy root culture of fenugreek (Trigonella foenum-graecum). J Med Plants 2016;15(59):73-80. 